\title{
CONJUGANDO, NA MODELAGEM MATEMÁTICA, O TEMA RELIGIÃO E ALGUNS DEBATES PARADIGMÁTICOS
}

\author{
Conjugating, in mathematical modeling, the theme religion and some \\ paradigmatic debates
}

\author{
Lênio Fernandes Levyl \\ Adílson Oliveira do Espírito Santo2
}

\section{RESUMO}

Nesta pesquisa, objetivou-se levar os alunos/sujeitos à compreensão de que há influências inextrincáveis entre o filosofar, em especial o filosofar epistemológico, e as demais manifestações culturais, com destaque para o matematizar. Quanto ao matematizar, objetivouse inserir o corpo discente em um processo de ensino-aprendizagem pautado pela modelagem de problemas do seu cotidiano e/ou do seu interesse, com ênfase no tema "Religião", o qual foi escolhido pelos próprios alunos. Nesse processo de modelagem, tornou-se central a discussão (que perpassa o âmbito epistemológico/paradigmático) sobre a importância ou não de serem conjugados conhecimentos afetos a campos disciplinares classificados convencionalmente como distintos. Enfim, no curso da referida dinâmica de modelagem, tentou-se fomentar o debate discente sobre paradigmas epistemológicos, sobre a oposição que existe, por exemplo, entre modernidade e complexidade.

Palavras-chave: Modelagem matemática; religião; paradigma.

\begin{abstract}
This research aimed to make the students/subjects understand that there are inextricable influences between philosophy, especially the epistemological philosophy, and other cultural events, such as the mathematizing. As for mathematizing, aimed to insert the students at a process of teaching and learning guided by modeling their daily problems and/or their problems of interest, enphasizing the theme "Religion", which was chosen by the students themselves. In this modeling process, it became central the discussion (which pervades the epistemological/paradigmatic ambit) about the importance or not of the conjunction of disciplines conventionally classified as distinct. Finally, in the course of that modeling dynamic, we tried to encourage a student discussion about epistemological paradigms, about the opposition that exists, for example, between modernity and complexity.
\end{abstract}

Keywords: Mathematical modeling; religion; paradigm.

\footnotetext{
${ }^{1}$ Mestre em Educação Matemáticas pela Universidade Federal do Pará (UFPA). Professor de educação Matemática do Instituto de Educação Matemática e Científica (IEMCI) da UFPA. E-mail: leniolevy@ig.com.br.

${ }^{2}$ Doutor em Engenharia Elétrica pela Universidade Estadual de Campinas (UNICAMP). Professor de Pós-Graduação do IEMCI / UFPA. Email: Adilson@ufpa.br.
} 


\title{
A PERGUNTA E A HIPÓTESE
}

A questão a que buscamos responder com esta investigação é/foi: "Como trabalhar o 'conhecimento do conhecimento' em um processo de ensino-aprendizagem pautado pela modelagem matemática?’.

No que diz respeito ao "conhecimento do conhecimento", voltamo-nos para o aspecto histórico-paradigmático. Movido por uma proposição de âmbito geral, mas que inclui a questão paradigmática, Morin afirma que:

\begin{abstract}
De fato, o conhecimento não pode ser considerado uma ferramenta ready made, que pode ser utilizada sem que sua natureza seja examinada. Da mesma forma, o conhecimento do conhecimento deve aparecer como necessidade primeira, que serviria de preparação para enfrentar os riscos permanentes do erro e da ilusão, que não cessam de parasitar a mente humana. Trata-se de armar cada mente no combate vital rumo à lucidez.

É necessário introduzir e desenvolver na educação o estudo das características cerebrais, mentais, culturais dos conhecimentos humanos, de seus processos e modalidades, das disposições tanto psíquicas quanto culturais que o conduzem ao erro ou à ilusão (MORIN, 2002, p.14).
\end{abstract} trabalho:

Engenhamos a seguinte hipótese visando à resposta da indagação que motivou este

"Mediante a associação intencional do pensar matemático com um pensar filosófico que favoreça a reflexão discente sobre paradigmas epistemológicos, em especial o da complexidade, quando da tentativa de construção, no ambiente pedagógico, de modelos matemáticos referentes aos objetos eleitos para estudo. A adesão crítica à concepção paradigmática complexa ajuda a situar em um contexto mais amplo os conhecimentos matemáticos e os recursos utilizados no processo de ensino-aprendizagem de matemática.”.

\section{A FUNDAMENTAÇÃO TEÓRICA}

A concepção de "complexidade" que norteou o presente trabalho baseou-se no corpo de idéias do filósofo, historiador, antropólogo e sociólogo francês Edgar Morin (1921 -), para quem:

\begin{abstract}
A separação sujeito/objeto é um dos aspectos essenciais de um paradigma mais geral de separação/redução, pelo qual o pensamento científico ou distingue realidades inseparáveis sem poder encarar sua relação, ou identifica-as por redução da realidade mais complexa à menos complexa. Assim, física, biologia, antropossociologia tornaram-se ciências totalmente distintas, e quando se quis ou quando se quer associá-las é por redução do biológico ao físico-químico, do antropológico ao biológico.

Precisamos, portanto, para promover uma nova transdisciplinaridade, de um paradigma que, decerto, permite distinguir, separar, opor e, portanto, dividir relativamente esses domínios científicos, mas que possa fazê-los se comunicarem sem operar a redução. $O$ paradigma que denomino simplificação (redução/separação) é insuficiente e mutilante. É preciso um paradigma de complexidade, que, ao mesmo tempo, separe e associe, que conceba os níveis de emergência da realidade sem os reduzir às unidades elementares e às leis gerais (MORIN, 2001, p.138).
\end{abstract}


Por sua vez, quanto à modelagem, à modelagem matemática e à modelagem matemática no processo de ensino-aprendizagem, levamos em consideração várias idéias de Bassanezi (2002) e de Biembengut \& Hein (2000).

A propósito:

A idéia de modelagem suscita a imagem de um escultor trabalhando com argila, produzindo um objeto. Esse objeto é um modelo. O escultor munido de material argila, técnica, intuição e criatividade - faz o seu modelo, que na certa representa alguma coisa, seja real ou imaginária. (...).

$\mathrm{Na}$ verdade o ser humano sempre recorreu a modelos, tanto para comunicar-se com seus semelhantes como para preparar uma ação. Nesse sentido, a modelagem, arte de modelar, é um processo que emerge da própria razão e participa da nossa vida como forma de constituição e de expressão do conhecimento (BIEMBENGUT \& HEIN, 2000, p.11).

Ademais: “(...) Um modelo matemático é um conjunto consistente de equações ou estruturas matemáticas, elaborado para corresponder a algum fenômeno - este pode ser físico, biológico, social, psicológico, conceitual ou até mesmo um outro modelo matemático" (BASSANEZI, 2002, p.174).

Finalmente:

De um ponto de vista sociocultural, não podemos antever as ações que os alunos desenvolvem quando convidados a modelar uma situação-problema. Certamente, podemos imaginar ações possíveis, inclusive com base na literatura, mas, uma vez que elas são situadas, não há como fazer previsões sobre suas ocorrências e sua ordem (BARBOSA, 2007, p.164).

\section{SOBRE MÉTODOS E METODOLOGIAS}

Buscamos fomentar um pensamento multidimensional em que dialogaram/dialogam o quantitativo e o qualitativo. A propósito:

Qual é o erro do pensamento formalizante quantificante que dominou as ciências? Não é, de forma alguma, o de ser um pensamento formalizante e quantificante, não é, de forma alguma, o de colocar entre parênteses o que não é quantificável e formalizável. O erro é terminar acreditando que aquilo que não é quantificável e formalizável não existe ou só é a escória do real. É um sonho delirante porque nada é mais louco do que a coerência abstrata (MORIN, 2001, p.188-189).

Malgrado as limitações que herdamos do paradigma da simplificação, limitações sempre presentes de um jeito ou de outro em nosso pensar e em nosso fazer, tentamos conduzir esta pesquisa em conformidade com os seguintes dizeres de Morin, Ciurana \& Motta:

Nada mais distante de nossa concepção do método do que aquela visão composta por um conjunto de receitas eficazes para chegar a um resultado previsto. Essa idéia de método pressupõe o resultado desde o início; nessa acepção, método e programa são equivalentes (...).

(...) É possível, contudo, outra concepção do método: o método como caminho, ensaio gerativo e estratégia "para" e "do" pensamento. O método como atividade pensante do sujeito vivente, não-abstrato. Um sujeito capaz de aprender, inventar e criar "em" e "durante" o seu caminho (MORIN, CIURANA \& MOTTA, 2003, p.17-18).

Ademais:

É verdade que os segmentos de estratégias bem-sucedidos no desenvolvimento de um método podem ser arquivados e codificados como segmentos programados para 
o futuro se as mesmas condições se mantiverem constantes. O método é uma estratégia do sujeito que também se apóia em segmentos programados que são revistos em função da dialógica entre essas estratégias e o próprio caminhar. $\mathrm{O}$ método é simultaneamente programa e estratégia e, por retroação de seus resultados, pode modificar o programa; portanto o método aprende (Ibidem, p.28).

\section{CONHECENDO A TURMA}

Nas páginas seguintes, relatamos as atividades compartilhadas com uma turma de um centro federal de educação, ciência e tecnologia de Belém, Pará entre os meses de junho e setembro de 2007 com vistas a respondermos à questão acima, que norteou a nossa investigação, sempre atentando para a verificação da hipótese correlata que havíamos formulado.

No dia 12 de junho de 2007, assumimos as aulas de matemática da turma CT1802I ${ }^{3}$ do referido centro federal, turma composta por 36 (trinta e seis) ${ }^{4}$ alunos do primeiro ano do Ensino Médio Integrado ao Curso Técnico de Mecânica.

Apresentamo-nos aos alunos e, de imediato, realizamos uma "avaliação diagnóstica" quanto à capacidade de eles relacionarem (i) matemática e outras áreas do conhecimento, (ii) matemática e realidade, (iii) outras áreas do conhecimento e realidade. Ademais, formulamos as seguintes perguntas a esses alunos: (iv) O que é concretude? (v) O que é abstração? (vi) A matemática é concreta ou é abstrata? (vii) Será que o conhecimento é construção humana? (viii) Ou será que o conhecimento é descoberta, é algo independente da elaboração? (ix) $\mathrm{O}$ homem é livre para criar, interpretar, intervir, influenciar? (x) Ou será que o determinismo vigora e exclui a possibilidade de livre-arbítrio? Os resultados dessa avaliação diagnóstica encontram-se disponíveis em Levy \& Santo (2007).

Após tomarmos ciência de algumas das opiniões epistemológicas prévias dos alunos dessa turma (na verdade, a análise detida das respostas discentes ao questionário diagnóstico ocorreu posteriormente a esse encontro), iniciamos um trabalho, junto a eles, com dinâmicas pedagógicas centralizadas no recurso da modelagem matemática. Voltamos notória atenção para o tópico "funções matemáticas" durante o processo de modelagem que integrou a pesquisa prática. Mesmo sabendo que um tema, ao ser modelado, suscita conhecimentos/relações que, muitas vezes, não se coadunam com as disciplinas e com as sequiências didáticas estabelecidas, o nosso intento foi aproveitar ao máximo os conhecimentos/relações habitualmente trabalhados no primeiro ano do Ensino Médio e nas séries anteriores (conhecimentos/relações que, em tese, os alunos egressos do Ensino Fundamental já dominam ou estão em vias de dominar), sem jamais desconsiderarmos (na medida em que a "complexidade" é uma das nossas idéias centrais) outros contextos/vínculos, matemáticos ou não, necessários à construção dos modelos.

\section{RELATO DOS PRIMEIROS ENCONTROS}

Em seguida à dinâmica do questionário diagnóstico, expusemos aos alunos, ainda em 12 de junho, qual iria ser o recurso de ensino-aprendizagem adotado: a modelagem matemática. Dissemos a eles, em linhas gerais, do que se tratava. Eles iriam inteirar-se de mais detalhes acerca desse tipo de procedimento pedagógico com o desenrolar das aulas. De

\footnotetext{
3 Esse código foi trocado para evitar identificação da turma e/ou dos alunos.

4 Apesar de haver 36 (trinta e seis) alunos regularmente matriculados na turma CT1802I, em função das faltas discentes nós contávamos habitualmente com cerca de (30) trinta estudantes em nossas aulas.
} 
início, ficaram sabendo que trabalhariam, em grande medida, a partir de temas ligados ao seu cotidiano e/ou ao seu interesse.

Ainda nessa primeira aula, pedimos a eles que se reunissem em grupos de três alunos e que escolhessem um tema para iniciarmos o nosso trabalho. Após muita troca de idéias, em ambiente de bagunça quase incontrolável, eles nos deram as seguintes sugestões:

"A expansão da zona periférica nos centros urbanos" (Loraine, Lúcia, Caio) ${ }^{5}$;

"Drogas e seus efeitos" (Sérgio, Miranda, Gladson);

"Religião" (Ivanildo, Diego, José);

“Arte paraense" (Luam, Felipe, Mariano, Claudiano);

"Violência" (Neivaldo, Roberto, Felipe);

"Falta de investimento na educação" (Airton, Marcus, Gabriel);

"Esporte" (Fernando, Augusto, Cassiano);

"Aquecimento global" (Paul, Vitório, Aldo);

"Macrodrenagem em Belém" (Taiguara, Adílio, Mikael).

Como tarefa de casa, pedimos a eles que, individualmente, aprofundassem seus conhecimentos quanto ao tema escolhido pelo seu grupo, lendo sobre esse tema na Internet, nos jornais, nas revistas, nos livros etc. Na aula seguinte (19/06), cada integrante do grupo iria socializar os novos conhecimentos com os outros dois colegas.

\section{REFLETINDO...}

Contudo, ao planejarmos em casa as dinâmicas para a aula do dia 19 de junho, refletimos a respeito da multiplicidade dos temas sugeridos pelos alunos e tomamos a decisão de trabalhar, dali em diante, com um tema de cada vez. Os grupos de três alunos seriam mantidos, mas todos os grupos trabalhariam com o mesmo tema. Os fatores que nos levaram a essa decisão foram, em primeiro lugar, o pressentimento da dificuldade que teríamos em acompanhar de forma satisfatória o desenvolvimento concomitante de tantos temas distintos, uma vez que o referido acompanhamento exigiria um esforço multiplicado no sentido de aprofundarmos, inclusive buscando links matemáticos, os nossos conhecimentos sobre os assuntos escolhidos, acrescentando-se a isso o fato de que, naquele momento, a nossa carga horária total não era desprezível (ministrávamos aulas, no referido centro federal, não apenas para turmas de nível médio/integrado, mas também para turmas de graduação). Em segundo lugar, destacamos os problemas que teríamos em administrar muitos temas ao longo de apenas duas horas-aula semanais.

\section{DE JUNHO: A ESCOLHA DE UM TEMA E DE UMA QUESTÃO}

No início da aula de 19 de junho, já considerando a referida mudança de planos, escrevemos no quadro os nove temas que os alunos haviam escolhido no encontro anterior e pedimos a eles que elegessem um daqueles assuntos para que iniciássemos os nossos trabalhos, mantendo-se a possibilidade de os demais temas serem abordados no futuro.

Com certa folga em seu favor, o tema escolhido para iniciarmos as nossas atividades foi "religião", seguido de longe por "aquecimento global". Alguns alunos disseram-nos que

\footnotetext{
${ }^{5}$ Optamos pela alteração dos nomes para que fosse mantido o anonimato dos alunos.
} 
isso se devia ao fato de vários dos seus colegas serem cristãos protestantes. Intimamente, tínhamos preferência pelo assunto "aquecimento global", mas decidimos respeitar a escolha da turma.

Fizemos uma breve exposição sobre o tema, ressaltando que deveria ser mais importante estudar o fenômeno da religiosidade em si, e os contextos com que tal fenômeno interage, do que procurar saber qual é a "melhor" ou a "pior" religião, se é que tal classificação é possível.

Pedimos aos grupos que se reunissem e elaborassem, na própria sala de aula, sínteses escritas do tema "religião", bem como 3 (três) perguntas que o envolvessem. Os textos nos foram entregues ao final da aula.

Entendemos que, em grande medida, as sínteses indicaram opiniões prévias baseadas em conhecimentos escolares e/ou em informações emanadas de meios de comunicação de massa. Pudemos destacar nelas os seguintes aspectos:

Ênfase na abordagem das religiões pelo prisma histórico ("origem e desenvolvimento das religiões"); pessoas");

Necessidade de as pessoas terem uma religião ("a religião como integrante da vida das

Complexidade religiosa causada pela complexidade/diversidade das culturas;

Ingerência da religião na união e/ou na desunião das pessoas e dos povos. Citação de conflitos ocorridos em função da religião, como a guerra entre palestinos e israelenses;

Conceituação de religião sob a ótica de alguma área de estudo, a exemplo da filosofia e das ciências ("a religião segundo a ciência"; "a religião segundo a filosofia").

As sínteses das opiniões prévias dos componentes dos grupos ficaram restritas a algumas relações e a alguns contextos, como o histórico, o sociológico e o antropológico, mas indicaram existir certo encadeamento lógico de idéias e certo amadurecimento a respeito do tema (a generalidade do assunto pode ter facilitado as manifestações a seu respeito), de tal forma que julgamos estarem os alunos dotados de condições básicas para a (re)construção de certos tópicos de matemática e de outras disciplinas a partir do tema "religião".

Foram elaboradas 27 (vinte e sete) questões (três por cada um dos nove grupos) afetas ao tema, das quais pedimos que a turma, através de votação individual, escolhesse uma para abordagem imediata. As demais questões poderiam ser abordadas em ocasiões futuras. Com certa margem em seu favor, venceu a questão: "Como você acha que a religião influencia a vida das pessoas?".

Ficou combinado que, ao longo dos dias que antecedessem a aula de 26 de junho, os grupos iriam providenciar o seguinte:

Pesquisa mais aprofundada do tema "religião";

Resposta, com base em seus conhecimentos prévios, à questão escolhida;

Pesquisa na Internet sobre "paradigma", "paradigma moderno/cartesiano" e "paradigma da complexidade".

Cada grupo traria uma redação a propósito das solicitações constantes nos itens segundo (resposta prévia) e terceiro (pesquisa na Internet). Deveria ser uma redação que não se restringisse à mera transcrição de trechos de livros, de revistas, de jornais ou de artigos da Internet. 


\section{DE JUNHO: ÚLTIMO ENCONTRO ANTES DO RECESSO}

$\mathrm{Na}$ aula de 26 de junho, recolhemos os trabalhos. Reservamos alguns dias do recesso de julho para a respectiva leitura, a qual nos conduziu a algumas conclusões. Antes de citálas, parece-nos importante mencionar que, em junho, ao longo das três semanas de aula até então decorridas, houve alterações na composição original de alguns dos grupos. Desde o primeiro encontro (12 de junho), solicitamos aos estudantes que tentassem manter a formação inicial das nove equipes com vistas a melhor acompanharmos o desenvolvimento de cada trio. Acontece que não é comum, no centro federal em questão (e nas demais instituições educacionais públicas), as mesmas presenças e ausências ${ }^{6}$ discentes de uma semana repetirem-se na semana seguinte, de tal sorte que, semanalmente, acontecem pequenas variações na configuração de uma turma, o que, conosco, verificou-se desde as primeiras aulas. Alguns dos trabalhos que recebemos no dia 26 de junho, por exemplo, não foram assinados por trios de alunos, tendo havido, no que se refere a essa tarefa, uma quantidade maior de grupos do que a existente no dia 12. Nos meses subseqüentes, o total de grupos fixou-se em dez, ou seja, um a mais do que o quantitativo com que iniciamos as nossas dinâmicas com a turma, sendo que alguns grupos, haja vista as faltas discentes e mesmo os abandonos de curso, nem sempre puderam contar com três componentes. Acreditamos que esse tipo de "desordem/incerteza" não prejudicou por completo a avaliação da evolução da turma como um todo, porquanto a média de freqüência às nossas aulas oscilava/oscilou entre 28 (vinte e oito) e 30 (trinta), dado um universo "inicial" de 36 (trinta e seis) alunos. Apesar da dificuldade ${ }^{7}$ de os mesmos três alunos reunirem-se seguidamente, aula após aula, cabianos, ainda assim, por conta do processo de avaliação dos grupos, continuar insistindo perante a turma no sentido da manutenção da referida união.

\section{OS CONHECIMENTOS PRÉVIOS COMO BASE PARA UM PRIMEIRO CICLO DE RESPOSTAS DISCENTES À QUESTÃO NORTEADORA DA PESQUISA}

Ao lermos as respostas à pergunta ("Como você acha que a religião influencia a vida das pessoas?") norteadora da modelagem, procuramos destacar a idéia central de cada uma delas, tendo elaborado os seguintes resumos, nos quais tentamos ser fiéis ao estilo literário e lógico dos textos que nos foram entregues em 26 de junho:

“A religião muda o pensamento e a consciência” (Adílio, Taiguara, Mikael);

"A religião exerce influência no sentido de que os indivíduos precisam de algo para acreditar e defender. Com vistas a isso, os líderes religiosos mostram todos os costumes e tradições que devem ser seguidos. A religião não influencia diretamente na vida. Isso depende do indivíduo" (Sérgio, Gleidson, Miranda);

"Nem tudo que vivemos, ou passamos, ou sentimos é religião, mas ela abrange grande parte da vida social e política da humanidade. Alguns acham que a religião é tudo, sendo, inclusive, capazes de morrer por ela. Já aqui no Brasil, não vemos isso (...)" (Romildo, Cláudio, Otaviano);

"A religião faz com que as pessoas amem mais e se sintam melhores. A religião dá forças para o enfrentamento de problemas, necessidades ou doenças" (Diego, José);

"A religião influencia os conceitos morais. O comportamento social da pessoa varia de acordo com a religião dela" (Felipe, Neivaldo, Roberto);

\footnotetext{
6 Tentamos reduzir o índice de faltas às aulas através da valorização da "chamada" e colocando-nos, nós próprios, como exemplo, uma vez que não tínhamos e não temos o hábito de faltar ou de chegar atrasados às aulas que ministramos.

7 Intensificada por eventuais problemas de relacionamento entre membros de uma mesma equipe.
} 
"A religião exerce influência através da fé, que é uma das coisas mais sagradas em nossas vidas" (Augusto, Fernando, Cassiano);

“A religião influencia na tomada de decisões. Ela indica o 'caminho certo'. Você faz coisas pela sua religião, como é o caso dos homens-bomba. Muitas pessoas acham que a religião não influencia em nada, mas ela influencia sim" (Paulo, Vitório, Aldo);

"A religião influencia a vida das pessoas em todos os sentidos, gerando fé, esperança, em que acreditar etc." (Caio, Loraine, Lúcia, Douglas, Ivanildo);

"A influência da religião depende da interpretação do indivíduo. Para alguns, pode ser motivo de guerra, para outros, de desenvolvimento, de respeito a regras como amar ao próximo..." (Gabriel, Airton, Marcus);

"O tipo de influência muda de acordo com a religião ou seita de que se estiver tratando. Mas, de modo geral, todos nós acreditamos em uma divindade que nos inspira a viver" (Luam, Felipe, Mariano).

Decidimos tomar esses depoimentos como respostas prévias dos estudantes e/ou dos grupos à indagação propulsora ("Como você acha que a religião influencia a vida das pessoas?") da referida dinâmica de ensino-aprendizagem com modelagem matemática, haja vista tratar-se de respostas baseadas em conhecimentos que eles possuíam por ocasião de nossos primeiros encontros. Estando esse trabalho de modelagem pronto ou adiantado em sua elaboração, caberia retornar ao ponto de partida para uma comparação entre os resultados auferidos e tais respostas.

De um modo geral, as redações não foram profundas, tendo-se voltado basicamente para os aspectos da fé e do bom comportamento gerado pela aceitação de uma determinada religião. Tratou-se, sem exceção, de opiniões pessoais acerca do tema "religião" e da pergunta norteadora da modelagem. Os trabalhos não ultrapassaram a extensão de uma lauda.

Contextos como o social e o político até foram citados, mas não se fizeram maiores referências às interações possíveis entre eles e outros âmbitos. Os alunos não analisaram as poucas relações que identificaram. Não percebemos uma "visão complexa" acerca da ingerência da religião/religiosidade na vida dos indivíduos.

As hipóteses discentes não foram conjugadas com conceitos científicos. Não esperávamos, contudo, mais do que esse tipo de resultado. Ainda estávamos adentrando com a turma, em junho, os rudimentos da pesquisa discente e dos debates epistemológicos/paradigmáticos.

Não houve o recurso discente a fontes (bibliográficas etc.) com o intuito de corroboração das opiniões manifestadas, o que se deveu, em parte, ao fato de que, de um modo geral, nos livros, nas revistas, na Internet etc., não é fácil a localização de textos que respondam diretamente à questão "Como você acha que a religião influencia a vida das pessoas?". Na atualidade, tornou-se comum os alunos recorrerem a fontes como a Internet em busca de alguma informação para "pesquisa" e, ao encontrá-la, transcreverem-na, dando a impressão posterior de haverem elaborado, eles próprios, o texto apresentado ao professor. Podemos afirmá-lo do alto da nossa experiência de alguns anos trabalhando com os ensinos públicos municipal, estadual e federal. No caso em foco, dada a dificuldade de encontrarem algo pronto na Internet ou em outro veículo de informação, possivelmente os alunos escreveram as respostas a partir de seus próprios pontos de vista, o que talvez explique aspectos como: os erros gramaticais; as respostas girando em torno de poucas relações e/ou de apenas um ou dois contextos; e a falta de profundidade das idéias expressadas. 
Por se tratar de uma pergunta relativamente específica ("Como você acha que a religião influencia a vida das pessoas?"), as respostas correspondentes, em nosso entendimento, apresentaram qualidade ligeiramente aquém daquela das redações elaboradas pelos alunos sobre "religião", que é um tema amplo. Lembremos, contudo, que as redações a propósito do assunto "religião" foram realizadas na própria sala de aula (no dia 19 de junho), trazendo certa dificuldade aos alunos, que dispuseram apenas de alguns minutos para concluílas e não tiveram, para tanto, a possibilidade de acesso a livros, a revistas, a jornais ou à Internet.

Quanto à segunda tarefa destinada aos grupos (ou seja, pesquisar sobre "paradigma", "paradigma moderno/cartesiano" e "paradigma da complexidade"), concluímos que todos simplesmente transcreveram textos da Internet, sem emitirem opiniões próprias. Os alunos da turma CT1802I pareciam enquadrar-se no "perfil geral" a que nos referimos linhas acima. Para eles, "pesquisar na Internet" era o mesmo que "localizar, copiar e colar". Entendemos que não se tratava de má fé, mas de ausência (mesmo após anos de estudos sistematizados) de uma orientação adequada acerca do que é o "processo de investigação". Como a "pesquisa discente" era um dos fundamentos do nosso recurso de ensino-aprendizagem, dispúnhamos de um tempo razoável para trabalhar com eles o seu significado dali em diante.

Finalizando o relato das nossas impressões sobre os trabalhos entregues pelos grupos no dia 26 de junho, achamos importante destacar que, apesar de limitados pela idéia de que pesquisar é "localizar, copiar e colar", é possível que alguns dos alunos tenham lido e internalizado os textos que extraíram da Internet ou de outra fonte informativa, posto que, nos momentos em que tratamos de "paradigmas" (também no dia 26), a participação/intervenção da turma foi expressiva.

No dia em foco, 26 de junho, travamos o nosso último contato com os estudantes da turma CT1802I antes do recesso de julho, lembrando que o ano letivo, com retomada das aulas em agosto, tinha o seu encerramento previsto para fevereiro de 2008, uma vez que havia começado em abril de 2007.

Quando desse último encontro, ainda não tínhamos procedido à leitura dos trabalhos a que nos referimos nos parágrafos anteriores, na medida em que os recebemos apenas em tal ocasião. Nesse encontro, abordamos os seguintes conteúdos, através de aula inicialmente "expositiva": produto cartesiano (definição e exemplos), relações (definição e exemplos) e funções (definição, exemplos e tipos de notação). Utilizamos, para exemplificar "função", o caso da variação da área de um quadrado de acordo com a variação do comprimento de seu lado.

Em seguida ao nosso recurso à didática expositiva, tentamos fomentar a "construção coletiva de conceitos", estimulando a turma a emitir hipóteses. Em certa altura, concluímos, nós e a turma, que o comportamento e o pensamento humanos podiam variar em "função" da religião ou da religiosidade. Concluímos juntos, mediante troca de idéias, que aspectos como estabilidade familiar, saúde, ciência, educação, política, economia, paz etc., podiam sofrer influência da religião/religiosidade.

Repassamos então aos grupos a seguinte tarefa (ainda sem estarmos a par, reiteramos, do conteúdo da "pesquisa" dos alunos acerca de "paradigma, paradigma moderno e paradigma da complexidade"), com previsão de entrega do relatório correspondente no primeiro dia de aula após o recesso:

"Através de acesso à Internet e/ou mediante visitas ao IBGE (Instituto Brasileiro de Geografia e Estatística), identificar tipos de comportamentos e/ou de pensamentos que sofrem a influência do aspecto religioso". 


\section{ALGUNS ASPECTOS DA CONSTRUÇÃO DO CONHECIMENTO NA SALA DE AULA}

Quanto à modelagem matemática no ensino e na aprendizagem, Biembengut \& Hein (2000) preconizam a apresentação/exposição ${ }^{8}$ de certos conteúdos matemáticos pelo professor-orientador à turma, tratando-se de conteúdos, conforme entendimento do professor, importantes para a elaboração do modelo pelos estudantes ou para o andamento da própria dinâmica de modelagem. Durante os nossos trabalhos com a turma CT1802I, houve certos momentos, devemos esclarecê-lo, em que lecionamos nos moldes expositivos, embora tentássemos, nessas ocasiões, relacionar os conteúdos com algum contexto não-matemático a fim de torná-los atraentes aos alunos.

Contudo, ao agir dessa maneira, não fomos movidos apenas pelo fator supramencionado, ou seja, pelo afã de municiar os estudantes quanto à modelagem. As pressões dos alunos para que cumpríssemos o programa, juntamente com a exigüidade do tempo semanal destinado aos nossos encontros com eles, também se constituíram em variáveis intervenientes. No que tange à utilização posterior de tais conteúdos pelos estudantes na dinâmica pedagógica da modelagem, procuramos deixar os grupos relativamente livres para as iniciativas que mais lhes conviessem.

Referindo-se a dificuldades que podem aparecer por ocasião da utilização da modelagem matemática no ensino e na aprendizagem, entre elas a "limitação temporal", Bassanezi sugere que:

A falta de tempo para "cumprir" um programa, a inércia dos estudantes para desenvolver a modelagem e a inexperiência de professores são dificuldades que podem ser minoradas quando modificamos o processo clássico de modelagem, levando-se em conta o momento de sistematização do conteúdo e utilizando uma analogia constante com outras situações problemas. (...) (BASSANEZI, 2002, p. $38)$.

\section{O CONHECIMENTO DO CONHECIMENTO}

Por ocasião de uma prática pedagógica de modelagem cujo foco era constituído pelo tema "religião" e pela pergunta "Como você acha que a religião influencia a vida das pessoas?", dado tratar-se de um tema e de uma pergunta marcadamente sociais e, portanto, distantes, à primeira vista, de um enquadramento matemático, talvez fosse apenas uma questão de tempo o surgimento, da parte dos alunos, de indagações como a seguinte:

Será que todos os aspectos de um fenômeno social, como é o caso do fenômeno da religiosidade, podem ser cabalmente matematizados?

Além do mais:

O modelo é representação ou é reflexo/cópia fiel do objeto estudado?

O modelo é construção ou é descoberta?

Em se tratando da modelagem, quais e como são os resultados de um estudo pautado pela fragmentação e pelo determinismo (em conformidade com o paradigma cartesiano), se comparados com os resultados de um estudo em que se considerem a distinção, a união e a criatividade/indeterminação (de acordo com o paradigma da complexidade)?

\footnotetext{
${ }^{8}$ Entendemos que o enfoque expositivo não é, em si, recriminável, desde que se acrescente à “exposição”, em algum momento, mesmo que posterior, o exercício da crítica, da reflexão, da criatividade e/ou da pesquisa.
} 
Confrontando os alunos com tais perguntas ou, quiçá, eles próprios as formulando antes de serem "provocados", o que esperávamos acontecer durante as dinâmicas pedagógicas vindouras, interessava-nos, em complemento ao processo e ao produto da modelagem de cada grupo da turma CT1802I, que esses estudantes construíssem um "conhecimento do conhecimento", o qual tenderia a elevar a sua consciência e a torná-los mais criteriosos.

\section{A IDEIA DE PARADIGMA}

Por oportuno, nos últimos minutos da aula do dia 26, buscamos trabalhar com os alunos a idéia de "paradigma". Ainda não havíamos lido os seus trabalhos sobre esse assunto. Ainda não sabíamos, portanto, acerca da "pesquisa" com base na tríade "localizar, copiar e colar". Perguntamos a eles o que entendiam a respeito de "paradigma". A discussão conduziu à enumeração de vários termos, entre eles "padrão" e "modelo". "Expusemos" em seguida algo acerca do "paradigma da modernidade", que relacionamos, a princípio, com "fragmentação", bem como acerca do "paradigma da complexidade", que associamos inicialmente a "contextualização". Em se tratando da pedagogia, citamos exemplos correspondentes a esses dois paradigmas: a aula tradicional de matemática, expositiva, fragmentária, determinista, acrítica e focalizada na memorização discente, de um lado, e a aula baseada na pesquisa, na contextualização/interação e na criatividade, de outro lado. Perguntamos-lhes qual dessas duas opções pedagógicas faz mais sentido para eles. Não exigimos uma resposta imediata. Pedimos tão somente que, daquele momento em diante, passassem a refletir a respeito.

\section{DE VOLTA Às AULAS}

As aulas foram retomadas na primeira semana de agosto. No dia 6, véspera do nosso primeiro encontro pós-férias com a turma, fomos abordados no corredor por um dos alunos. Ele nos pediu para não ser identificado perante os demais. Disse-nos que a turma estava descontente com o recurso didático adotado e que no dia seguinte, quando da aula, haveria uma conversa conosco a respeito, na qual os alunos iriam pedir que passássemos a ministrar aulas através do "método tradicional". Sabendo disso, tivemos algumas horas para refletir sobre os argumentos que utilizaríamos durante a negociação com eles sobre a manutenção (ou não) do recurso didático. Sendo assim, foi bom esse aluno ter-nos abordado de antemão.

\section{DE AGOSTO: DIA DE NEGOCIAÇÃO}

Logo que entramos na sala, conforme imaginávamos, os alunos pediram para conversar conosco. Entre outras coisas, disseram que não estavam naquele centro federal de estudos apenas para realizar um curso técnico, mas que também desejavam cursar, posteriormente, uma universidade. Sentiam-se prejudicados em relação às demais turmas, cujo desenvolvimento do conteúdo programático, segundo eles, encontrava-se adiantado em relação ao da CT1802I.

Após as suas colocações, achamos por bem expor as nossas. Explicamos-lhes que só havíamos tido, nós e a turma, três aulas juntos. Tudo ainda estava incipiente. Reiteramos (já que havíamos falado sobre isso em junho) que uma diferença favorável, em nossa opinião, ao recurso de ensino-aprendizagem que estávamos tentando adotar na sua turma, em comparação com o chamado "método tradicional", consistia no fato de o aluno, conforme esse "novo recurso pedagógico", ser um partícipe mais ativo no que diz respeito à aquisição/elaboração 
do próprio conhecimento, em processo no qual o professor desempenhava o papel de "orientador".

Prometemos-lhes que, mesmo continuando a adotar esse processo de ensinoaprendizagem diferente do habitual e não tão imediato assim em termos da obtenção de resultados/produtos, faríamos um grande esforço para não perder de vista os aspectos básicos do conteúdo programático.

Diante dos nossos argumentos, a turma decidiu dar-nos um voto de confiança. Se, no futuro, entendessem que as coisas não estivessem caminhando bem, voltaríamos a conversar a respeito.

Um detalhe que nos pareceu ter sido determinante para que eles se queixassem do processo pedagógico adotado foi o fato de termos-lhes solicitado que visitassem o IBGE no mês de julho e lá obtivessem informações com vistas à resposta da questão propulsora da pesquisa. Possivelmente eles não estavam acostumados aos esforços demandados por uma dinâmica pedagógica baseada na perquirição. De certa forma, são oportunas as seguintes palavras de Bassanezi:

(...) O uso de Modelagem foge da rotina do ensino tradicional e os estudantes, não acostumados ao processo, podem se perder e se tornar apáticos nas aulas. Os alunos estão acostumados a ver o professor como transmissor de conhecimentos e quando são colocados no centro do processo de ensino-aprendizagem, sendo responsáveis pelos resultados obtidos e pela dinâmica do processo, a aula passa caminhar em ritmo mais lento (BASSANEZI, 2002, p.37).

Outro aspecto que nos pareceu ter contribuído para o seu descontentamento foi o fato de, na última aula de junho, termos afirmado que vincularíamos em parte os resultados da primeira avaliação bimestral, que ainda estava pendente, ao julgamento dos frutos, mesmo que parciais, da investigação dos grupos. Em 7 de agosto, refletindo (na ação) a respeito desse seu descontentamento, sugerimos que poderiam acessar pela Internet o banco de dados do IBGE, sem a obrigatoriedade da realização de uma visita ao Instituto. Outra coisa: pedimos a eles que não trabalhassem apenas em função das notas, mas que não faltassem às aulas, que participassem ativamente dos nossos debates e/ou construções e que os grupos nos entregassem os trabalhos escritos tempestivamente. Por tratar-se de uma busca contínua de aprimoramento, eles seriam convidados diversas vezes, no futuro, a repensar as respostas apresentadas em seus trabalhos, sempre sendo considerados, para tanto, os conhecimentos de que, paulatinamente, estavam se apropriando e/ou que estavam construindo. O acordo inicial, então, basicamente não mudou, porém deixamos claro para a turma que as regras eram passíveis de certa negociação.

Quanto ao desenvolvimento do conteúdo durante a aula desse dia, 7 de agosto (a discussão supramencionada tomou quase metade do tempo da aula), vimo-nos obrigados a conduzir as dinâmicas em um ritmo mais acelerado do que o habitual. Cremos haver sacrificado parcialmente a autonomia construtiva dos alunos, pois, em alguns momentos, não os estimulamos suficientemente a refletirem e a se manifestarem. Ademais, por conta da pressão exercida minutos antes pela turma, cuja sensação desagradável nos acompanhou intimamente até o final do encontro, a aula teve um quê de tradicional. Isso nos frustrou. Mesmo assim, o conteúdo construído, dizendo respeito basicamente às funções constante, afim e quadrática (cujas formas de notação/representação também foram trabalhadas, com destaque para tabela, diagrama de setas, par ordenado, lei de formação e gráfico cartesiano), 
foi marcado por contextualizações, sobretudo na física e na química. Abordamos também as noções de domínio e imagem, além da idéia de função contínua e função discreta.

Por causa do tempo reduzido, alguns procedimentos que havíamos incluído em nosso plano de aula para esse dia não foram levados a efeito, reforçando a tese de que cada momento pedagógico é único, não sendo o futuro previsível de modo cabal. Por exemplo, tínhamos a intenção de ler, uma por uma, todas as redações que os grupos nos haviam entregado em junho e nas quais opinaram a propósito das influências da religião/religiosidade na vida das pessoas. A idéia, nesse caso, era fazê-los comparar o seu pensamento correlato daquela época (pouco sistematizado) com a sua opinião atual, principalmente se já tivessem realizado algum levantamento estatístico em julho, conforme combinado antes das férias. Infelizmente, não houve tempo para lermos os textos e refletirmos a respeito. Também não conseguimos trabalhar com eles as idéias de paradigma, de paradigma da modernidade e de paradigma da complexidade, que constavam na parte final do plano de aula.

\section{DE AGOSTO: A OLIMPÍADA DE MATEMÁTICA}

Em 14 de agosto, não ministramos aula para a turma em função da primeira etapa da Olimpíada Brasileira de Matemática das Escolas Públicas, que ocorreu no dia e na hora previstos para a aula.

\section{PLANEJAMENTO DE AULA: "UMA ILHA DE CERTEZA EM UM MAR DE INCERTEZAS"}

No que tange à turma CT1802I, normalmente "planejávamos" as aulas (que ocorriam às terças-feiras) no final de semana imediatamente anterior ao encontro. Quando elaboramos o plano da aula do dia 21 de agosto, pela primeira vez resolvemos subdividir as dinâmicas obedecendo a intervalos de tempo. De fato, um plano de aula, convencionalmente, exige tais subdivisões. É bem verdade que, no mais das vezes, aquilo que se espera não acontece em sua totalidade, sendo que, por esse motivo, éramos/somos particularmente flexíveis em relação a planejamentos. Conforme Morin \& Kern:

\footnotetext{
Há uma relação de incerteza entre a idéia e o real. A idéia pode se impor ao real, mas nem por isso este se conformará á idéia. Os rebentos produzidos pelas copulações entre o real e a idéia não se assemelham a nenhum dos dois genitores (...).

(...) O que é possível? Nem tudo é possível num momento dado, mas não sabemos quais as fronteiras que separam o possível do impossível (MORIN \& KERN, 2002, p.127).
}

Na medida em que os fenômenos naturais e sociais são complexos (no sentido da teoria da complexidade de Edgar Morin), há que se admitir a existência simultânea da ordem e da desordem em ambos os tipos de fenômenos, os naturais e os sociais. A ordem contrapõese à desordem, mas a complementa em vez de anulá-la, de tal forma que o planejamento sempre é bem vindo desde que se tenha consciência da permanente necessidade de se conciliá-lo com as mudanças de rota que os aspectos inusitados da dinâmica pedagógica suscitam.

\section{DE AGOSTO}


Em 21 de agosto, conseguimos dedicar os primeiros cinqüenta minutos de aula à construção de conteúdos matemáticos, e os cinquienta minutos restantes a discussões acerca do tema (Religião), da pergunta (Como você acha que a religião influencia a vida das pessoas?) e de questões paradigmáticas. A prévia divisão temporal desse encontro (no plano de aula) e o esforço para segui-la mostraram-se satisfatórios. Parece-nos que sem o planejamento dessa divisão e sem esse esforço levaríamos todos os cem minutos de que dispúnhamos discutindo apenas os conteúdos matemáticos. Se a observância ao tempo previsto não foi de todo exata, ao menos evitou disparates.

$\mathrm{Na}$ primeira parte da aula de 21 de agosto, buscamos tratar de algumas idéias matemáticas novas para os alunos, apelando, na medida do possível (haja vista a limitação imposta pelo tempo de duração total do encontro), à sua participação e à utilização de links envolvendo a matemática e outras disciplinas, dessa vez, em especial, a física. Os conteúdos abordados disseram respeito a: exemplos de função constante, afim e quadrática, definição e exemplos de função par/ímpar, definição e exemplos de função crescente/decrescente.

$\mathrm{Na}$ segunda parte do encontro, afora a realização de discussões epistemológicas com a turma, solicitamos aos grupos que nos entregassem os resultados escritos do trabalho combinado com eles em junho, isto é, que nos entregassem as respostas à questão ${ }^{9}$ acerca do tema religião, sendo que apenas dois dos nove grupos trouxeram o material. Acordamos com a turma que os demais grupos trariam os seus trabalhos na aula da semana seguinte.

Achamos interessante destacar as falas de três alunos, ocorridas durante a segunda parte da aula de 21 de agosto. Um deles acreditava existirem pontos positivos e pontos negativos na fragmentação do conhecimento. Um ponto positivo, segundo ele, era que dessa forma seria possível ao estudioso, ao cientista ou ao técnico aprofundar-se bastante em determinado campo do saber. Um ponto negativo era que o sujeito que assim agisse ficaria impossibilitado de tomar decisões ou de conhecer aspectos que envolvessem âmbitos mais abrangentes do que o de sua área de estudo. Um segundo aluno, com menos eloqüência do que o primeiro, identificou-se com a importância de se unirem conhecimentos com vistas à solução de problemas. Um terceiro aluno afirmou algo que nos pareceu deveras interessante, antecipando uma questão que pretendíamos abordar em encontros posteriores com a turma. Conforme esse aluno, por mais que uma aula fosse marcadamente tradicional, quem sabe não seria possível ao estudante, em contato com os assuntos que lhe estavam sendo "repassados" (mesmo que houvesse o objetivo docente/institucional explícito de que tais assuntos não fossem criticados), exercer um senso crítico a respeito, inclusive subsidiado por leituras e/ou por acesso a outras fontes? De nossa parte, havíamos achado esse posicionamento interessante. Não nos aprofundamos mais na questão porque outros alunos pediram, ou melhor, tomaram a palavra, alguns deles já agitados e (infelizmente) ansiando pelo término da aula (os nossos dois horários de aula eram os últimos do turno vespertino).

\section{AINDA EM 21 DE AGOSTO}

Nesse dia 21 de agosto, entre o trabalho com o conteúdo programático (primeiros cinqüenta minutos) e os debates que marcaram a segunda parte do encontro, nós lemos para os alunos algumas das respostas prévias (cerca de quatro delas) que os grupos haviam elaborado em junho à questão norteadora da nossa pesquisa. A idéia era mostrar a eles (uns não sabiam, possivelmente, quais tinham sido as respostas dos outros) o que pensavam durante as primeiras aulas, em junho, sobre a pergunta ("Como você acha que a religião influencia a vida das pessoas?") norteadora da modelagem, a fim de que comparassem tais

\footnotetext{
9 "Como você acha que a religião influencia a vida das pessoas?"
} 
pensamentos com o que achavam do tema e da pergunta/questão nesse novo momento, decorridas já algumas aulas de matemática acerca de funções e algumas conversas sobre paradigmas epistemológicos. Nós dissemos a eles que solicitaríamos, como futura tarefa, que novamente tentassem responder à supracitada pergunta. $\mathrm{O}$ objetivo era que, ao longo do tempo, das aulas e/ou das suas aquisições/construções cognitivas, as respostas se tornassem cada vez melhor elaboradas.

Dissemos a eles que faríamos uma comparação entre as respostas que nos haviam sido entregues no mês de junho (primeiro ciclo de respostas), das quais lemos algumas em voz alta, conforme dito acima, e as respostas (segunda sequiência de respostas) que nos foram trazidas nessa data, 21 de agosto, somadas àquelas que nos seriam dadas em 28 de agosto, prazo limite para entrega dos trabalhos ainda pendentes. Apenas faríamos essa comparação quando dispuséssemos dos nove trabalhos. Deixamos claro para a turma que a tendência de sistematização progressiva dessas respostas devia/podia ser acompanhada do auxílio da matemática. Quanto a outras áreas do conhecimento serem ou não utilizadas para ajudar na resposta a tal pergunta, talvez as reflexões que realizamos nesse dia ( 21 de agosto) acerca dos paradigmas moderno e complexo tenham-lhes despertado alguma idéia do melhor caminho a seguir.

\section{QUESTIONAMENTOS E REFLEXÕES}

Por fim, achamos cabível a citação das perguntas e reflexões de que tratamos nos cinqüenta minutos finais da aula desse dia:

Para responder à questão "Como você acha que a religião influencia a vida das pessoas?”, é possível utilizar a noção de função matemática?

Se você utilizar a matemática para responder a essa questão, somente ela, a matemática, será suficiente para a sua resposta? Ou você também precisará ou poderá fazer uso de outras disciplinas, de outros conhecimentos?

Você consegue se aprofundar em um assunto, um tema ou uma questão utilizando apenas a matemática, ou apenas a física, ou apenas a química, e assim por diante?

Ou será que para entender melhor um assunto, você deve interligar conhecimentos?

Afirmação: "Paradigma Epistemológico" é um conjunto de princípios que se acredita regerem a aquisição e o desenvolvimento do conhecimento.

Afirmação: O paradigma que vigora (sobretudo no mundo ocidental) desde o século XVII é o "paradigma da modernidade". Um dos princípios desse paradigma é separar um problema em partes e estudá-las isoladamente. O cardiologista estuda o coração, o oftalmologista os olhos, e assim por diante.

Quais são, em sua opinião, os pontos positivos e negativos da fragmentação dos conhecimentos?

Você entende melhor a matemática quando a estuda isoladamente ou quando a estuda através de exemplos práticos, associando-a, digamos, à física, à química etc.?

\section{DE AGOSTO: MENOS TEMPO DO QUE O HABITUAL}

Em 28 de agosto, os alunos nos pediram para serem dispensados às $17 \mathrm{~h} 30$ porque teriam que assistir a uma palestra sobre "segurança do trabalho". Por esse motivo, e também por conta de nossa participação ao longo de toda a semana seguinte (inclusive durante o 
horário marcado para a aula com a turma CT1802I) no V Encontro Paraense de Educação Matemática (V EPAEM), nós decidimos marcar uma aula extra para o sábado, ou seja, para o dia $1^{\circ}$ de setembro. Em 28 de agosto, como o nosso tempo de interação foi reduzido pela metade, nós não conseguimos tratar de tudo o que havíamos incluído no plano da respectiva aula. O tempo foi suficiente apenas para trabalharmos a definição de função sobrejetora e para explorarmos dois exemplos práticos correlatos, um deles extraído de Bassanezi (2002), tratando do crescimento da população mundial desde 1804, e o outro (tendo como fonte o IBGE-PNAD, 2002) acerca da elevação, com o decorrer do tempo, do número de famílias no Brasil com pessoas de referência do sexo feminino. O restante do planejamento destinado originalmente a essa aula ( 28 de agosto) foi transferido para a aula extra do sábado seguinte.

Nesse dia (28 de agosto), mais três grupos entregaram-nos o trabalho relativo à resposta da questão "Como você acha que a religião influencia a vida das pessoas?". Porquanto ainda faltavam quatro textos a serem entreguem, dilatamos o prazo para o sábado ( $1^{\circ}$ de setembro).

\section{$1^{\circ}$ DE SETEMBRO: NA SALA DE AULA OU NA QUADRA DE FUTEBOL?}

Dia $1^{\circ}$ de setembro. Manhã de sábado. É/era cada vez mais aceitável por nós a idéia de que os momentos pedagógicos são únicos, a exemplo do fato inesperado de uma parte dos alunos da turma ter planejado jogar futebol na quadra do centro federal no mesmo dia e na mesma hora da aula marcada por nós com a anuência deles próprios na terça-feira anterior. Cerca de metade da turma dispôs-se a assistir à aula. Reinava, porém, certo estado de agitação na sala. Um grupo formado por estudantes que resolveram não participar do nosso encontro ficou por alguns minutos em um corredor próximo à sala, pressionando, verbal e gestualmente, os colegas que nela estavam para que fossem ao jogo de futebol, sem qualquer preocupação com a nossa presença, ali, naquele momento, sem qualquer preocupação com uma possível desaprovação nossa em relação à sua atitude, em relação à atitude de alunos ingressos havia apenas seis meses em uma instituição pública que talvez fosse a mais conceituada do Pará em termos de ensino médio.

Nossa experiência nos indica que, ao longo dos três anos em que os alunos freqüentam o centro federal, convivendo com seus pares, com professores e demais servidores da instituição, eles tendem a amainar esse tipo de irreverência, não por conta de coações que se lhes imponham, mas por estabelecerem um contato quase contínuo com uma comunidade estudantil ou um grupo cultural que, malgrado certas extravagâncias, não compactua em geral com comportamentos extremados. Lembrando que estávamos lidando com alunos matriculados na instituição havia uns poucos meses, mais uma vez fazia-se oportuna a máxima de "dar tempo ao tempo".

Quanto aos estudantes que permaneceram na sala (em $1^{\circ}$ de setembro), tentamos retomar a abordagem de conceitos matemáticos interrompida no dia 28 de agosto: função injetora, função bijetora e função inversa. Dessa vez, buscamos respeitar mais ainda o tempo de elaboração dos conhecimentos por eles, estimulando-os sobremaneira a perguntarem e a opinarem. Tais conhecimentos poderiam vir a ser úteis na elaboração de modelos proposta em junho e/ou nas respostas à questão: "Como você acha que a religião influencia a vida das pessoas?".

\section{CONVERSANDO (E PERGUNTANDO) UM POUCO MAIS SOBRE FRAGMENTAÇÃO E CONTEXTUALIZAÇÃO}


Objetivávamos dedicar a segunda parte do encontro, ou seja, os últimos cinqüenta minutos de aula, aos contextos filosófico-epistemológicos componentes da nossa hipótese ${ }^{10}$ explicativa da questão ${ }^{11}$ motivadora desta investigação. Como restavam apenas trinta minutos para o encerramento da aula - não alcançamos naquele dia, em nossa prática pedagógica, o que planejáramos, sendo corroborada novamente "a certeza da incerteza" -, pedimos a eles que respondessem ao menos às duas primeiras de um total de oito questões formuladas para 0 encontro:

O paradigma da modernidade prega a contextualização ou a fragmentação dos conhecimentos? Dê alguns exemplos. exemplos.

E quanto ao paradigma da complexidade, o que ele apregoa? Forneça também alguns

As demais seis (6) questões constavam em um texto que elaboramos e lhes entregamos ao final da aula. Não houve tempo para que elas fossem trabalhadas no referido encontro, mas pedimos-lhes que as lessem em casa e refletissem a respeito, dada a previsão de abordarmolas na aula seguinte.

Durante os minutos em que os grupos (ou o que havia sobrado deles, visto que muitos estudantes aderiram ao jogo de futebol) tentaram responder à primeira e à segunda questões, percebemos que a maioria havia esquecido o que eram modernidade e complexidade. Não tinham olvidado que uma delas tratava da fragmentação e a outra, da contextualização/união. Mas qual dizia respeito a quê? Por esse motivo, tivemos que trabalhar alguns exemplos com eles, tentando não responder às questões em seu lugar, contudo.

No fim de semana posterior (dias 8 e 9 de setembro), iniciamos a análise das respostas elaboradas em agosto pelos estudantes à questão norteadora da pesquisa demandada a eles. Passados cerca de dois meses entre a primeira e a segunda opiniões da turma acerca do assunto, além do fato de havermos trabalhado, nós e eles, no citado ínterim, a matemática de maneira não-fragmentada, tendo abordado também algumas noções de epistemologia, estávamos, pois, curiosos quanto às novas (se é que seriam novas) respostas da turma à pergunta "Como você acha que a religião influencia a vida das pessoas?".

\section{ALGUMAS CONCLUSÕES}

De um modo geral, nos trabalhos escritos que foram trazidos pelas equipes em fins de agosto, manifestaram-se mais formalismo e complexidade do que naqueles elaborados no mês de junho.

Havíamos orientado previamente as equipes quanto ao significado de "pesquisar". Mas houve grupos que recorreram, por exemplo, à Internet com o intuito de apenas "copiar e colar" ("Control C e Control V", em "internetês"). Isso não escapou à nossa percepção em

\footnotetext{
10 "Mediante a associação intencional do pensar matemático com um pensar filosófico que favoreça a reflexão discente sobre paradigmas epistemológicos, em especial o da complexidade, quando da tentativa de construção, no ambiente pedagógico, de modelos matemáticos referentes aos objetos eleitos para estudo. A adesão crítica à concepção paradigmática complexa ajuda a situar em um contexto mais amplo os conhecimentos matemáticos e os recursos utilizados no processo de ensino-aprendizagem de matemática".

11 Questão: “Como trabalhar o 'conhecimento do conhecimento' em um processo de ensino-aprendizagem pautado pela modelagem matemática?".
} 
função da qualidade dos estilos literários e dos encadeamentos de idéias, os quais superaram, nesses casos, as manifestações habituais da média da turma. Algumas equipes chegaram a identificar, em seu trabalho escrito, a fonte bibliográfica, procedimento correto, não fosse o fato de os seus textos terem se restringido a meras transcrições de tais fontes.

Houve, entre os que "copiaram e colaram", aqueles que se esforçaram para conjugar comentários a propósito de religião/religiosidade com textos que incluíam tabelas estatísticas (e/ou representações de "funções matemáticas") sobre o assunto. Eles freqüentemente ressaltaram e/ou tentaram justificar os benefícios de se contextualizarem conhecimentos. Apesar do excesso de transcrições, o esforço em criar vínculos cognitivos constituiu-se, assim cremos, em um aspecto louvável.

Para nós, a conclusão mais interessante advinda da comparação que realizamos entre os trabalhos de junho e os de agosto foi confirmar, quanto aos de agosto, uma mobilização geral da turma objetivando responder à questão proposta ("Como você acha que a religião influencia a vida das pessoas?") de modo mais sistematizado, tentando elaborar (fato discutível, entretanto, no que tange às meras transcrições) vínculos com contextos diversos, inclusive o matemático.

Por fim, no que tange à possibilidade de associação discente intencional entre modelagem e reflexões paradigmáticas, embora a turma tenha participado, desde junho/2007, de debates e de trabalhos acerca de paradigmas epistemológicos, em especial abordando questões inerentes à modernidade e à complexidade, a dificuldade em conjugar tais estudos com a modelagem e/ou com o tema da modelagem foi notória em suas respostas de agosto à pergunta "Como você acha que a religião influencia a vida das pessoas?". Em momentos posteriores $^{12}$ a agosto/2007, chegamos a lograr êxito mais evidente nessa empreitada. Frisamos que os resultados narrados ao longo das páginas anteriores referem-se a processos inclusos em uma investigação mais ampla, cujo término ocorreu apenas em fevereiro de 2008.

\section{REFERÊNCIAS}

BARBOSA, Jonei Cerqueira. A prática dos alunos no ambiente de modelagem matemática: o esboço de um framework. In: BARBOSA, Jonei Cerqueira; CALDEIRA, Ademir Donizeti; ARAÚJO, Jussara de Loiola. Modelagem matemática na educação matemática brasileira: pesquisas e práticas educacionais. Recife: SBEM, 2007, p.161-174.

BASSANEZI, Rodney Carlos. Ensino-aprendizagem com modelagem matemática. São Paulo: Contexto, 2002.

BIEMBENGUT, Maria Salett; HEIN, Nelson. A modelagem matemática no ensino. São Paulo: Contexto, 2000.

LEVY, Lênio Fernandes. A modelagem matemática no processo de ensino-aprendizagem e o conhecimento do conhecimento. In: Anais do II Encontro Paraense de Modelagem Matemática no Ensino. ISSN: 1982-8691. Belém, Pará, 2008.

LEVY, Lênio Fernandes; SANTO, Adílson Oliveira do. Primeiro passo para uma experiência de modelagem matemática. In: Anais da V Conferência Nacional Sobre Modelagem na Educação Matemática. ISBN: 978-8598601-15-1. Ouro Preto, Minas Gerais, 2007.

MORIN, Edgar. Ciência com consciência. 5. ed. Rio de Janeiro: Bertrand Brasil, 2001. . Os sete saberes necessários à educação do futuro. 6.ed. São Paulo: Cortez, 2002.

MORIN, Edgar; KERN, Anne Brigitte. Terra-pátria. 3.ed. Porto Alegre: Sulina, 2002.

\footnotetext{
12 Conforme anunciado em Levy (2008).
} 
Conjugando, na modelagem matemática, o tema religião e alguns debates

MORIN, Edgar; CIURANA, Emílio-Roger; MOTTA, Raúl Domingo. Educar na era planetária: o pensamento complexo como método de aprendizagem pelo erro e incerteza humana. São Paulo: Cortez; Brasília, DF: UNESCO, 2003. 